\title{
A Comparative Study of Paper-based and Computer-based Contextualization in Vocabulary Learning of EFL Students
}

\author{
Mousa Ahmadian \\ Dept. of English Language and Literature, Arak University, Arak, Iran \\ E-mail: M-ahmadian@araku.ac.ir \\ Majid Amerian \\ Dept. of English Language and Literature, Arak University, Arak, Iran \\ E-mail: amerian1383@yahoo.com \\ Ahmad Goodarzi (Corresponding author) \\ Dept. of English Language and Literature, Arak University, Arak, Iran \\ E-mail: Ahmad.goodarzi1234@gmail.com
}

Doi:10.7575/aiac.alls.v.6n.2p.96

Received: 25/11/2014

URL: http://dx.doi.org/10.7575/aiac.alls.v.6n.2p.96

Accepted: $31 / 01 / 2015$

\begin{abstract}
Vocabulary acquisition is one of the largest and most important tasks in language classes. New technologies, such as computers, have helped a lot in this way. The importance of the issue led the researchers to do the present study which concerns the comparison of contextualized vocabulary learning on paper and through Computer Assisted Language Learning (CALL). To this end, 52 Pre-university EFL learners were randomly assigned in two groups: a paper-based group (PB ) and a computer-based (CB) group each with 26 learners. The PB group received PB contextualization of vocabulary items, while the $\mathrm{CB}$ group received $\mathrm{CB}$ contextualization of the vocabulary items thorough PowerPoint (PP) software. One pretest, posttest, along with an immediate and a delayed posttest were given to the learners. Paired samples t-test of pretest and posttest and independent samples t-test of the delayed and immediate posttest were executed by SPSS software. The results revealed that computer-based contextualization had more effects on vocabulary learning of Iranian EFL learners than paper-based contextualization of the words.
\end{abstract}

Keywords: Computer-based contextualization, Paper-based contextualization, Vocabulary learning, CALL

\section{Introduction}

Teaching Vocabulary has always been tedious work for teachers and a stressful task for learners (Krashen et al., 1989; Schmitt 2000; Nation \& Waring, 2001; Ellis, 1995). After years of being neglected and receiving little attention, second language (L2) vocabulary instruction have now become the center of attention of many applied linguists and language teachers (Decaricco, 2001, Barcroft, 2004; Read, 2004).

In vocabulary learning, context has a significant part both in helping students learn new words and in setting up how vocabulary is manipulated in communication and writing. According to Moras (2001), the most essential features of vocabulary teaching is to encourage the students, so that they can develop their vocabulary by themselves. Over the last twenty years, much research relating to acquisition of vocabulary in context has been done (Beck et al. 1983; Snow \& Burn et al. 1998; Larson \& Marsh 2005).

Technological developments have an important capability of expanding every field of study. No need to say, language teaching is one of the fields that have been influenced by these new technological achievements. Computer Assisted Language Learning (CALL) has long been studied by many researchers. One of the sub-fields of CALL is computerbased vocabulary instruction (CBVI). Researchers working in the area of CBVI try to examine beneficial ways for language learners to learn L2 vocabulary by manipulating technology. The need for using CBVI in language classes convinced the researchers to compare teaching contextualized vocabulary on paper and contextualized vocabulary through CBVI.

\section{Review of Related Literature}

\subsection{Vocabulary Learning}

Generally, vocabulary is defined as a system of words with of their meaning explanations. A word is, typically, signified as a set of features in which there is the mixture of its meaning, association, collocation, grammatical behavior, written form (spelling) (Schmitt, 2000). In some previous approaches to language teaching, it was believed that once L2 learners have covered particular words, they have learnt them. They do not do any more studies to recall and use them in other contexts. However, they may not remember some of the learned vocabulary either partially or 
entirely. It has been shown that Mnemonic strategies and spaced repetition are useful techniques to make sure of learning of newly-covered words for a longer time (Ellis, 1995; Schmitt, 2000).

There exist conflicting views among language professionals concerning the relative superiority of two approaches to learning second language vocabulary: learning words in contexts (contextualized learning) vs. learning words out of contexts (decontextualized learning). Whereas the discussions regarding contextualized vs. decontextualized vocabulary leaning has yet to be resolved, a useful third way to teach vocabulary is emerging via research achievements. This approach amalgamates vocabulary instruction in context and out of it.

In a study by Khuwaileh (1995) examined the impact of vocabulary in context at the intermediate level of English for academic purposes in an experiment with Jordanian university students $(\mathrm{N}=40)$. He provided two lists of twenty words. The words in first list included English meaning and were discussed in Arabic; in the second list the words were in a text for silent reading, it also had vocabulary quizzes. After 14 weeks, the learners were given a text of the words on list 1 and a second text including the words of list 2. The correct answers to each list were examined and it showed that the mean of correct answers was 9.3 for list 1 and 14.04 for list 2, revealing an apparent advantage of vocabulary in context for comprehension, retention and or recall.

Meara et al. (1995) also claim that presenting vocabulary in list form is an effective way that helps the learners to learn a large number of words in a very short time. Hulstijn (2001) states that if the exposure of learners to a rich body of lexicon which is a need for fluent communicational activities, practices such as habitual rehearsal of words, rote learning, and automatic word recognition should be included in the program.

Nowadays, vocabulary learning has been helped by new techniques of teaching vocabulary, one of which is using the computer to teach or learn language. This area will be elaborated on, in the following section.

\subsection{Computer-assisted Language Learning (CALL)}

CALL is defines concisely by Levy (1997:1) as "the search for and study of applications of the computer in language teaching and learning". CALL has been used in second language (L2) and foreign language (FL) learning with programs which supplies a range of multimedia practices. Among studies of vocabulary retention, researchers have presented guidelines for designing of Computer-assisted programs for vocabulary retention. For example, Goodfellow (1994) recommends that computer-assisted programs of vocabulary learning should meet the learner's need to create a extensive L2 mental vocabulary, to guarantee interactivity in choosing, processing the words, to develop a long lasting retention; to underpin learning processes which concentrates on the target-words; to identify and support modification of surface retention approaches, and to create and store data on learning approaches and end results.

There exist some empirical vocabulary studies which relate to the expansion of the programs of computer-assisted vocabulary learning. In a survey monitoring L2 students' use of a software program with an on-line dictionary, Bland et al. (1990) consider the form of learners' searching as an manifestation oftheir vocabulary learning. The results of two studies by Coady et al. (1993) propose working on high-frequency vocabulary through CALL is advantageous.

Kang (1995) did a survey on elementary school students that knew English alphabets were familiar with sentence structures of English to examine contextualized vocabulary learning through CALL. The findings revealed that the computer-based group which benefited context method outperformed any other group in a retention test. This proposes that contextualized vocabulary in CALL environments can extends vocabulary retention.

The need for helping vocabulary learning in classes and the trend of using computers in language classes made convincing reasons for the researchers to find the answer to the following question:

-Is computer-based instruction of vocabulary in context more effective than paper-based vocabulary instruction in context in vocabulary learning of EFL students?

Based on the research question, the following null-hypothesis was put forward for the above question to be tested.

Computer-based contextualization has no significant effect on vocabulary learning of Iranian EFL students compared with paper-based contextualization of vocabulary.

\section{Methodology}

The study was done in a high school in Doroud, Iran, with two groups of Persian speaking English learners of two intact classes: one PB group and one CB group, who aged 16-17. The number of students in each group was 30 at first. After the Michigan Test of English Language Proficiency (MTELP) (1982) to measure the subjects' proficiency level, four students of each group were eliminated due to their very high or low proficiency level. This was done through elimination of the subjects who scored 1.5 standard deviation above or below the mean.

In addition to the MTELP (1982), a pre-test of vocabulary recognition based on Vocabulary or knowledge rating (Blachowicz et al., 1986) was administered. This is a before reading strategy designed to evaluate students' vocabulary knowledge. Students were given a list of words to rate how well they knew each word. This scale includes four columns for each word to fill: the word, known, unknown, and meaning. This scale was used as a pre-test to examine whether the students knew the selected words or not. The vocabulary items in the scale were chosen from the pre-university English textbook of the educational system of Iran. As the pretest, 70 vocabulary items were chosen from the second part of the pre-university English book. After the administration, ten words known by the learners were eliminated from the pretest, and at last, a 60 item test remained for the post test. 
The immediate post-tests included 10 vocabulary items which were covered in each session of both classes. They were administered at the end of each class in each session. The scores of the immediate post-tests of each person were summed and considered as each person's immediate post-test score. Naturally, this score was ranged from 0 to 60 .

The delayed post-test included 60 vocabulary items which were covered during the six sessions of instruction in both classes. Before giving the tests to the subjects, the test was given to a group of 30 English students in a language institution twice with a week interval to evaluate test reliability, item difficulty, and item facility. After the first administration, the test's item difficulty and item facility were examined, then, some items were replaced due to very high item difficulty or facility. The second administration helped the researchers to access an approximately acceptable item difficulty and facility and also a high Cronbach Alpha reliability of 0.73 .

The pretest was correlated with vocabulary section of Nelson proficiency test (extracted from Nelson English Language Tests, by Fowler \& Coe (1976)), and showed the correlation of 0.81whcih was an acceptable rate correlation.

In this study, tasks and materials were the same for both groups, differing in means of presentation. The experimental group used computers (PowerPoint software) to get along with the vocabulary items, but for the control group there were just ordinary ways of teaching materials for vocabulary instruction, such as paper and pen.

Before starting the instruction, both groups were given instructions on how to use contexts to guess the meanings of some given words; this was done during two one-hour sessions. The context clues were synonyms, antonyms, general contexts, and examples. The PB group received paper-based context for vocabulary learning and the CB group received computer-based context. This teaching process lasted 3 weeks. The PowerPoint file was given to the students of the CB group. They were taught how to use the file. The file had the bolded word at the top. After each session, a 10-item vocabulary quiz was taken to check students' short term learning. The students in the PB group were also grouped into 13 groups of 2 to control the effect of grouping in both groups. The process was the same for the PB group, but in the PB group, all the materials, the picture, question, direction, definition, and pronunciation were on paper. The teacher's directions in both groups were meticulously controlled, in a way that the teacher mentioned everything in each group. At the end, both groups received the post-test to assess the possible effects of teaching vocabulary in context and computer-assisted vocabulary teaching.

\section{Results}

After the instruction period, for each student, four scores were available, one pretest, and three posttests, namely, vocabulary knowledge posttest, multiple-choice immediate and delayed posttests. The quantitative analyses of the collected data were calculated with the aid of computer. SPSS was used for this purpose. Then, independent-samples ttest and paired-samples t-test were used to compare the scores of the two groups. The results are tabulated in the following tables.

The comparison of the pre- and post-tests of the $\mathrm{PB}$ and $\mathrm{CB}$ groups revealed a remarkable achievement in leaning vocabulary items. The pre-test and post-test mean values of 4.07 and 45.61 as well as an acceptable level of $p=0.00$ show a great development in the learning of the vocabulary items in the CB group (Table 1). The paired-samples t-test for the performance of the PB and CB groups on the post-test is shown in Table 1 Considering what is indicated in the table, we can find the following results: Sig. $=$ p-value $=0.000<0.05$.

Table 1. Results of Paired Samples test of the PB and CB Groups on the Pre and Posttests

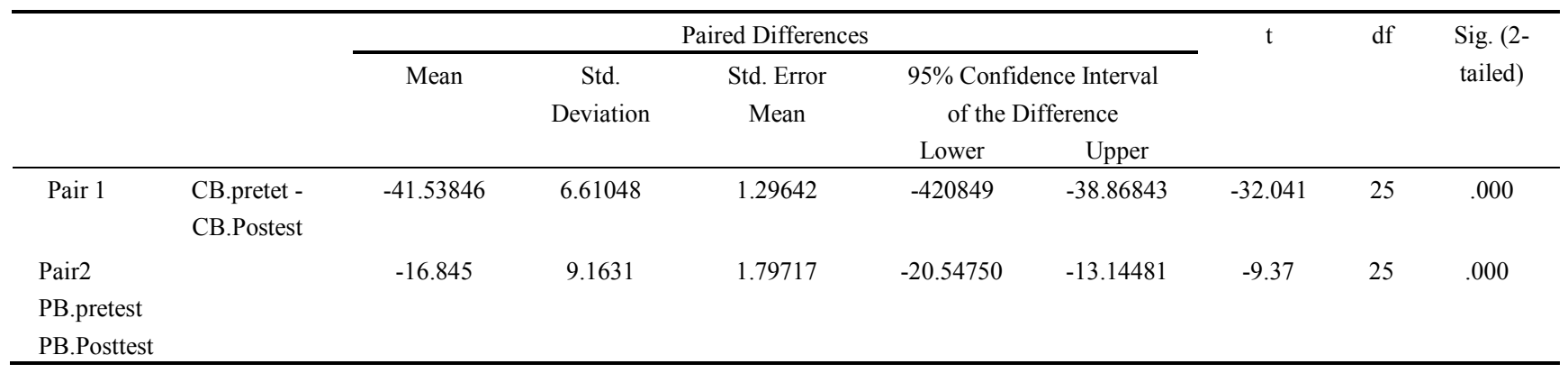

The $\mathrm{p}=$ value of 0.00 in the PB group signifies that the teaching process was also successful in the PB group, but the difference between means of pretest and posttest in the CB group was significantly more than that of the PB group (CBmean difference $=41.54$, PB-mean difference $=16.85$ ). The paired-samples $t$-test for the performance of the PB group on the post-test is shown in table (1). Considering what is shown in the table, we can find the following results: Sig. = pvalue $=0.00>0.05$. The results reveal that both groups had proven improvements in vocabulary leaning.

To answer the research question, an independent sample test was used. The results of post-tests were analyzed to compare the PB and CB groups' vocabulary learning of the students. Table 2 displays the post-test results for the PB and $\mathrm{CB}$ groups. The estimated mean and standard deviation of the learning of vocabulary items in the CB group amounted to be 45.61 , and 5.89, respectively, and that of the participants in the PB group amounted to be 21.69 and 
8.15 , respectively. Analysis of the mean scores showed that there was a considerable difference between the PB and the $\mathrm{CB}$ groups in terms of learning the vocabulary items.

Table 2. Independent Samples t-test Performance of the Participants on the Post-test

Levene's Test for Equality of

Variances t-test for Equality of Means
95\% Confidence

Interval of the

\begin{tabular}{cccccccccc} 
& & & & & Sig. $(2-$ & Mean & \multicolumn{2}{c}{ Std. Error } & \multicolumn{2}{c}{ Difference } \\
\cline { 7 - 10 } & $\mathrm{F}$ & Sig. & $\mathrm{T}$ & $\mathrm{df}$ & tailed) & Difference & Difference & Lower & Upper \\
\hline $\begin{array}{c}\text { Equal variances } \\
\text { assumed }\end{array}$ & 5.302 & .025 & 12.122 & 50 & .000 & 23.92308 & 1.97355 & 19.95908 & 27.88 \\
\hline $\begin{array}{c}\text { Equal variances } \\
\text { not assumed }\end{array}$ & & & 12.122 & 45.54 & .000 & 23.92308 & 1.97355 & 19.94946 & 27.89 \\
\hline
\end{tabular}

The independent-samples t-test for the performance of the CB and the PB groups on the pre-test is shown in Table 2. Considering the results: Sig. $=$-value $=0.025<0.05$, reveal that improvements in vocabulary learning of the $\mathrm{CB}$ group were much more than that of the PB group.

In an attempt to analyze the results of the study, two other multiple-choice posttests were used. The first was given after each session of instruction and the second was administered after the whole process of the study. An independent samples t-test ran to compare the result of delayed posttest in the PB and CB groups.

The analysis of independent-samples t-test of delayed posttest in Table 3 showed that the difference between the performance of the $\mathrm{PB}$ and $\mathrm{CB}$ groups was statistically significant $(\mathrm{p}=0.035)$, that is, the subjects in the CB group outperformed the PB group.

Table 3. Independent Samples t-test Performance of the Participants on the Delayed Post-test

\begin{tabular}{|c|c|c|c|c|c|c|c|c|c|}
\hline & $\begin{array}{r}\text { Levene's Test for Ec } \\
\text { of Variances }\end{array}$ & uality & & & \multicolumn{3}{|c|}{ t-test for Equality of Means } & & \\
\hline & \multirow{2}{*}{ 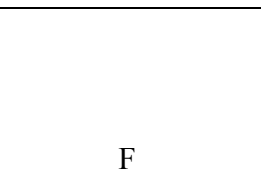 } & \multirow[b]{2}{*}{ Sig. } & \multirow[b]{2}{*}{$\mathrm{t}$} & \multirow[b]{2}{*}{$\mathrm{df}$} & \multirow{2}{*}{$\begin{array}{l}\text { Sig. }(2- \\
\text { tailed) }\end{array}$} & \multirow{2}{*}{$\begin{array}{c}\text { Mean } \\
\text { Differenc } \\
\mathrm{e}\end{array}$} & \multirow{2}{*}{$\begin{array}{l}\text { Std. } \\
\text { Error } \\
\text { Differe } \\
\text { nce }\end{array}$} & \multicolumn{2}{|c|}{$\begin{array}{l}95 \% \text { Confidence } \\
\text { Interval of the } \\
\text { Difference }\end{array}$} \\
\hline & & & & & & & & Lower & Upper \\
\hline $\begin{array}{l}\text { Equal variances } \\
\text { assumed }\end{array}$ & 4.716 & .035 & 12.208 & 50 & .000 & 23.19231 & 1.89981 & 19.37642 & 27.0819 \\
\hline $\begin{array}{l}\text { Equal variances } \\
\text { not assumed }\end{array}$ & & & 12.208 & 45.858 & .000 & 23.19231 & 1.89981 & 19.36786 & 27.0175 \\
\hline
\end{tabular}

The significance and meaningfulness of the scores of the CB and PB groups in the immediate posttest were calculated through an independent samples t-test. The P-value of independent samples t-test showed really close amount to acceptability of significance (Sig. $=0.052 \geq 0.05$ ), but it was 0.002 higher than the acceptable value of P (Table 4 ). The mean difference of 22.57 and the p-value of 0.05 revealed that the $\mathrm{CB}$ group performed much better than the $\mathrm{PB}$ group in the immediate posttest.

Table 4. Independent Samples t-test Performance of the Participants on the immediate Post-test

\begin{tabular}{|c|c|c|c|c|c|c|c|c|c|}
\hline & \multicolumn{4}{|c|}{$\begin{array}{c}\text { Levene's Test for } \\
\text { Equality of Variances }\end{array}$} & \multicolumn{3}{|c|}{ t-test for Equality of Means } & \multirow{2}{*}{\multicolumn{2}{|c|}{$\begin{array}{l}95 \% \text { Confidence } \\
\text { Interval of the } \\
\text { Difference }\end{array}$}} \\
\hline & & & & & \multirow{2}{*}{$\begin{array}{l}\text { Sig. (2- } \\
\text { tailed) }\end{array}$} & \multirow{2}{*}{$\begin{array}{c}\text { Mean } \\
\text { Difference }\end{array}$} & \multirow{2}{*}{$\begin{array}{l}\text { Std. Error } \\
\text { Difference }\end{array}$} & & \\
\hline & $\mathrm{F}$ & Sig. & $\mathrm{t}$ & df & & & & Lower & Upper \\
\hline $\begin{array}{c}\text { Equal variances } \\
\text { assumed }\end{array}$ & 3.957 & .052 & 12.166 & 50 & .000 & 22.57692 & 1.85576 & 18.84 & 26.30 \\
\hline $\begin{array}{l}\text { Equal variances } \\
\text { not assumed }\end{array}$ & & & 12.166 & 46.620 & .000 & 22.57692 & 1.85576 & 18.84 & 26.31 \\
\hline
\end{tabular}


To answer the research question, the researchers presented all the above obtained data via tables. Based on the results, we can say that there are significant differences between the PB and CB groups. That is, the results of the paired samples and independent samples t-tests revealed that the learners in the $\mathrm{CB}$ group outperformed the learners of the $\mathrm{PB}$ group in this study.

\section{Discussion}

Based on the results of analyses and considering the research question, one may infer that the computer-based contextualization vocabulary teaching does have significant effects on the learners' vocabulary learning compared with paper-based contextualization vocabulary teaching. The results approve the findings of the prior studies in this area (Cellat, 2008; Kılıçkaya \& Krajka, 2010; Hulstijn et al., 1996; Chun \& Plass, 1996) showing that the CAVI group learned and retained more vocabulary than teacher-led group.

The results suggest that implementing CB contextualization of vocabulary teaching can help the students improve their vocabulary learning. Although both $\mathrm{PB}$ and $\mathrm{CB}$ groups received the same length of time instruction and teaching materials, the $\mathrm{CB}$ group revealed higher improvement, and their mastery of the vocabulary items was gained from their interaction via computer-based contextualization of the words. Therefore, one can argue that $\mathrm{CB}$ instruction causes such a progress.

The findings of the study approve Ghabanchi and Anbarestani (2008) who examined the effects of call program on expanding lexical knowledge of EFL Iranian intermediate learners. Their results revealed that that in using CALL program, learners have an intensive mental processing which results in long term recall of words.

The findings of the present investigation are in line with Kang (1995) who carried out a study on elementary school students who had basic knowledge of the English alphabets and sentence structure. His findings suggested that the presentation of vocabulary with visual, aural and sentence contexts in computer-assisted learning environments enhances vocabulary learning. The results of the present study also confirm Najafi's (2012) findings, who examined the effects of CALL Multimedia (Still-Picture and Motion-Picture Multimedia) on the vocabulary learning of elementary students. The results of his study revealed that the Motion-Picture Multimedia Program (MPMP) was more effective than the Still-Picture Multimedia Program (SPMP) in enhancing EFL learner's repertoire of vocabulary. The findings also support the results of Naraghizadeh et al.'s (2013) study examined the effect of CALL on the vocabulary learning of Iranian EFL learners and found that the group who received Computer Assisted Language Learning outperformed that who did not receive.

Barani (2013) also came to some similar findings when he studied the impact of CALL on vocabulary achievement of Iranian university EFL learners and observed that there was a significant difference between CALL users and nonusers groups $(\mathrm{p}<0.05)$.

Based on the findings of this study and what Lyman-Hager claims, computerized presentation is more appealing for both learners and teachers. Unlike traditional presentation of vocabulary on paper, the computer-based presentation was much more exciting for the learners of this study. As such, Davis et al. (1997) believe and what was revealed in the present study, the computer's capabilities let the user to store more considerable comprehension than printed forms do. This helps the vocabulary learners to get more involved with learning, and consequently, more learning happens.

This study confirms that one of the salient features which is put forward by many researchers, such as Wood (2001), AlSeghayer (2001), is the capabilities of computer to adjoin meaning to the multimodal manifestation of any type of teaching materials to make learning more permanent.

As the results of the present study suggest, there could be some explanations for the superiority of CALL over the traditional paper-based procedure of teaching materials. Nowadays, the lights of technology are shining almost everywhere. Nearly all language learners and teachers are familiar with computer-based technologies and the Internet. This familiarity makes them mentally more ready to show a more tendency to work with them. This could be viewed from different aspects; of which might be the multimedia aspects of CALL that help the learners work with language tasks in a cyber-world which provides a transposition of those visual concepts to the mental concepts in the learner's mind. Mayer and Sims (1994) believe that one of the applications of a multimedia program is to give the learners the opportunity of constructing referential links between two types of mental manifestation systems: the verbal and the visual ones. These referential links are more facilitating when both modes of verbal and visual mediums are provided in parallel, as it was used in this research.

Further, the results of the study suggest that CALL programs such as motion pictures and colorful slides are more helpful in teaching lexical items than a picture on paper in the textbooks for EFL students. In this regard, Al-Seghayer (2001) states, motion pictures better build a mental image, better build inquisitiveness leading to extended focusing, and embody a favorable mixture of modalities.

The results of the study is in harmony with Kim and Gilman (2008) who carried out a study on 172 middle school students to examine the effects of visual texts on vocabulary learning. The results their study lead one to conclude that an effective way to develop of English vocabulary learning is to present graphics that show what the vocabulary means.

Moreover, in this study, the students showed to recall more vocabulary items when computer-assisted programs were used. The diversity of modality cues in CALL is able to help the students produce meaningful linkage between words and their meaning, and consequently, let them experience an in-depth leaning. Chun and Plass (1996) posit that this is due to the fact that the words are codified in two modes (visual and textual), consequently, they are internalized better 
than one mode codified words. Dual coding brings more ease for extracting meaning, and as such, provides learners with building two kinds of cues for recall in that memory. Linking vocabulary items with different kinds of media promotes intensiveness of recall cues and extends the vocabulary learning. Multimodal features not only keep students actively engaged in learning, but also grant a great deal of learning styles by presenting several positions: When the learners are trying to work with words in context through computers, they can see the words' form, type them, and cut and paste them in some other pages, the ability of the learners for learning can be dramatically increased.

From another point of view, CALL helps learners to be autonomous in learning (Qian, 1996). This does not mean that the language teachers are not needed anymore, nor does it imply that there should be no syllabus for learning. It posits that the language teachers need to manage the students' learning and be as a model of learning for them. If the learners are well-guided in the CALL classes, leaning could flow easily at home and in front of their computers.

\section{Conclusion and Implications}

This study, although limited in scope, was an attempt to investigate the impact of computer-based contextualization on promoting the vocabulary learning of Iranian EFL learners compared to paper-based contextualization. The survey indicated the significant effects of computer technology on their vocabulary learning. The results provided evidence that those learners who use computer technology to learn vocabulary show more vocabulary retention than those who do not, this means that computer technology has a positive and significant effect on the vocabulary learning of EFL students.

The study also reveals that a portion of motion and creativity in presetting vocabulary items to the students and using common software such as PowerPoint could come in hand. The software was used because it is nearly available to all language teachers. Colors, movements, sounds, and the excitement of using computers to learn would itself provide more conditions for learning vocabulary, as what was done and revealed in this study.

A great number of views can be found by getting students to use computers to learn vocabulary in context. Information from such studies provisions valuable data on the leaners' vocabulary learning and how they improve it. The findings may be of relevance to teachers in better understanding of the CBI of vocabulary and the way of implementing CBI in language classes. The type and amount of CBI of vocabulary in this study may give teachers a measure when deciding how much time to dedicate to vocabulary. Reports of research findings such as these are likely to encourage teachers to feel confident applying CBI to their classrooms. Simple creativity from the teacher side may bring about incredible results. Using computer software to teach is one of the ways to change the conditions of the present time in Iran's educational system, especially in the area of TEFL. Replication of the research is clearly needed before the given conclusions could be advocated with confidence.

\section{References}

Al-Seghayer, K. (2001). The effect of multimedia annotation modes on L2 vocabulary acquisition: A comparative study [Electronic version]. Language Learning \& Technology, 5(1), 202-232.

Barcroft, J. (2004). Effects of sentence writing in second language lexical acquisition. Second Language Research, 20(4), 303-334.

Barani.G. (2013). The Impact of Computer Assisted Language Learning (CALL) on Vocabulary Achievement of Iranian University Students EFL Learners. International Journal of Basic Sciences \& Applied Research. Vol., 2 (5), 531-537.

Beck, I. L., McKeown, M. G., \&McCaslin, E. S. (1983). Vocabulary: All contexts are not created equal. Elementary School Journal, 83, 177-181.

Blachowicz, C.L.Z., Peter J.L. Fisher, Donna Ogle, and Susan Watts-Taffe. (2006). Vocabulary: Questions from the Classroom. Reading Research Quarterly 41 (4): 524-539.

Cellat, S. (2008). Computer assisted vocabulary learning: A study with Turkish 4th grade EFL learners. (Unpublished master's thesis). Anadolu University, Eskişehir.

Chun, D., \&Plass, J. (1996). Effects of multimedia annotations on vocabulary acquisition. The Modern Language Journal, 80(2), 183-198.

Coady, J. and Huckin, T. (1997). Second Language Vocabulary Acquisition. Cambridge University Press, Cambridge.

Coady, J., Magoto, J., Hubbard, P., Graney, J., \&Mokhtari, K. (1993). High frequency vocabulary and reading proficiency in ESL readers. In T. Huckin, M. Haynes, \& J. Coady (Eds.), Second language reading and vocabulary.

Chun, D. M., \& Plass, J. L. (1996). Effects of multimedia annotations on vocabulary acquisition. The Modern Language Journal, 80(2), 183-198.

Davis, N., \& Lyman-Hager, M. (1997). Computers and L2 reading: Student performance, student attitudes. Foreign Language Annals, 30 (1), 58-72.

Decaricco, J. (2001). Vocabulary learning and teaching. In M. Celce- Murcia, (Ed), Teaching English as a second or foreign language, (pp.285-299), Boston, MA: Heinle\&Heinle.

Ellis, N. (1995). The psychology of foreign language vocabulary acquisition: Implications for CALL. Computer Assisted Language Learning, 8,103-128. 
Fisher, E. (1993). The Teacher's Role. In Scrimshaw, P. (Ed).Language, Classroom \& Computers. London and New York: Routledge.

Fowler, W.S. \& Coe, N. (1976). Nelson English Language Tests. Canada: Thomas Nelson and Sons Ltd.

Ghabanchi. Z. \& Anbarestani. M. (2008). The effects of call program on expanding lexical knowledge of EFL Iranian intermediate learners. The Reading Matrix, Vol. 8, No. 2

Goodfellow, R. (1994). Design principles for computer aided vocabulary learning. Computers and Education, 23, 5362.

Goodfellow, R. \&Laurilard, D. (1994). Modelling learning processes in lexical CALL. CALICO Journal, 11, 19-46. Retrieved from: http://calico.org/

Hoeflaak, A. (2004). Computer-Assisted Training in the Comprehension of Authentic French Speech: A Closer View. Computer Assisted Language Learning 17:3, 315-337.

Hulstijn, J. H. (2001). When do foreign-language readers look up the meaning of unfamiliar words? The influence of task and learner variables. Modern Language Journal, 77, 139-147.

Hulstijn, J., Hollander, M., \& Greidanus, T. (1996). Incidental vocabulary learning by advanced foreign language students: The influence of marginal glosses, dictionary use, and reoccurrence of unknown words. The Modern Language Journal, 80(3), 327-339.

Kang, S. -H. (1995).The effects of a context-embedded approach to second-language vocabulary learning. System, 23 , 43-55.

Khuwaileh, A. A. (1995). Words and context in EFL. Grazer Linguistics Student, 44, 27-36.

K1lıçkaya, F., \& Krajka. J. (2010). Comparative usefulness of online and traditional vocabulary learning. The Turkish Online Journal of Educational Technology, 9(2), 55-63.

Kim, D., \& Gilman, D. A. (2008). Effects of Text, Audio, and Graphic Aids in Multimedia Instruction for Vocabulary Learning. Educational Technology \& Society, 11 (3), 114-126.

Krashen, S. D. and Terrell, T. D. (1989). The Natural Approach: language acquisition in the classroom. Pergamon: Prentice Hall.

Larsen-Freeman, D. (2000). Techniques and Principles in Language Teaching. $2^{\text {nd }}$ Ed. UK: Oxford University Press.

Larson, J., \& Marsh J. (2005). Making literacy real: Theories and practices for learning and teaching.).). Thousand Oaks: Sage.

Levy, M. (1997). Computer assisted language learning: Context and conceptualization. Oxford: Oxford University Press.

Mayer, R. E., \& Sims, V. K. (1994). For whom is a picture worth a thousand words? Extensions of a dual-coding theory of multimedia learning. Journal of Educational Psychology, 86, 389-401.

Moras, S. (2001). Teaching Vocabulary to Advanced Students: A Lexical Approach.

http://www.telus.net/linguisticsissues/teachingvocabulary.html

Najafi., Sh. (2012). The Effects of CALL Multimedia (Still-Picture and Motion-Picture Multimedia) on the Vocabulary Learning of Elementary Students. Unpublished MA thesis. Azerbaijan: Shahid Madani University.

Naraghizadeh.M,\&Barimani.S. (2013). The Effect of CALL on the Vocabulary Learning of Iranian EFL Learners. Journal of Academic and Applied Studies. Vol. 3(8) August 2013, pp. 1-12.

Nation, I. S. P. \&Waring, R. (2001). Vocabulary size, text, text coverage and wordlists. In N. Schmitt and M. McCarthy (Eds.), Vocabulary: Description, acquisition, and pedagogy. Cambridge: Cambridge University Press.

Qian, D.D. (1996). ESL vocabulary acquisition: Contextualization and de-contextualization. The Canadian Modern Language Review, 53 (1), 120-142.

Read, J. (2004). Research in teaching vocabulary. Annual Review of Applied Linguistics, 24,146-161.

Schmitt, N. (2000). Key concepts in ELT: Lexical chunks. English Language Teaching Journal 54, 4: 400-401.

Schmitt, N. (2002).Vocabulary in language teaching. Cambridge: Cambridge University Press.

Snow, C.E., M.S. Burns, \& P. Griffin (Ed.).(1998). Preventing reading difficulties in young children. Washington, DC: National Academy Press.

Snow, C.E., and Young-Suk Kim.( 2007). Large Problem Spaces: The Challenge of Vocabulary for English Language Learners. New York: Guilford Press.

Swan, M., \& Walter, C. (1984). The Cambridge English Course. Cambridge: University Press.

Waring, R. (2004). A study of receptive and productive learning from word cards. Studies in Foreign Languages and Literature, 21(1), 94-114.

Wood, J. (2001). Can software support children's vocabulary development? LLT journal, 5(1), 166-201 URL:http://11t.msu.edu. 